\title{
Abstracts of Papers \\ Twenty-fifth Annual Albert L. Tester Memorial Symposium, 13-14 April 2000
}

\begin{abstract}
The Albert L. Tester Memorial Symposium is held in honor of Professor Albert L. Tester, who, at the time of his death in 1974, was senior professor of zoology at the University of Hawai'i at Mānoa. The faculty and students of the Department of Zoology proposed an annual symposium of student research papers as a means of honoring, in a continuing and active way, Dr. Tester's lively encouragement of student research in aspects of biology. Papers reporting original research in all aspects of biology, solicited from graduate students at the university, are presented at the spring-semester symposium. Income from contributions to the Albert L. Tester Memorial Fund of the University of Hawai'i Foundation provides two prizes for the best papers. Judges include representatives of the Department of Zoology faculty, winners from the preceding symposium, and a distinguished scholar from another university, who also presents a major symposium address. In 2000 John Endler, Department of Biological Sciences, University of California, Santa Barbara, participated in the Symposium.
\end{abstract}

\section{The Mesopelagic Community and Spinner Dolphin Foraging Kelly 7. Benoit Bird ${ }^{2}$}

The mesopelagic boundary community $(M B C)$ in the Hawaiian Islands is an important food resource for many organisms, including spinner dolphins (Stenella longirostris). To understand the role of this community in the feeding ecology of spinner dolphins, spatial and temporal patterns in the density and relative abundance of these organisms were characterized using acoustic sampling. A fishfinder modified to sample directly into a laptop computer was used to survey the $\mathrm{MBC}$ off the leeward coasts of O'ahu, Hawai'i, Maui, and Lāna'i from dusk until dawn. Visual, passive acoustic, and sonar sightings of spinner dolphins were also recorded. Both relative abundance and density measurements

${ }^{1}$ Manuscripts accepted 1 May 2000.

${ }^{2}$ Department of Zoology and Hawai'i Institute of Marine Biology, University of Hawai'i at Mānoa, Honolulu, Hawai'i 96822. Sponsor: Whitlow Au.

Pacific Science (2001), vol. 55, no. 1:99-110 (C) 2001 by University of Hawai'i Press All rights reserved suggest that the $\mathrm{MBC}$ undergoes a substantial horizontal migration every evening, in addition to its well-documented vertical migration. Because of this horizontal migration, the boundary community is found much closer to shore than previously reported. This movement toward shore raises questions about the accepted model of spinner dolphin foraging in Hawai'i. Observations of spinner dolphins suggest a more complex foraging pattern, compatible with patterns observed in their food resource. However, although major spatial and temporal patterns in the $\mathrm{MBC}$ are consistent between islands, the boundary community is spatially heterogeneous both horizontally and vertically. The parameters of patch structure vary significantly throughout a night and between islands. It is likely that spinner dolphin foraging tactics vary with these changing parameters both within and between islands. A preliminary assessment of these foraging variations indicates differences in absolute depth and vertical position of foraging animals relative to the vertical distribution of the MBC. 


\section{Environmental Impact of an Open-Ocean Aquaculture Cage on the Benthic Community \\ David R. Bybee ${ }^{3}$}

A large oceanic aquaculture cage has been placed approximately 1.5 miles offshore of 'Ewa Beach on the south shore of O'ahu, Hawai' $\mathrm{i}$. It is completely submerged in $31 \mathrm{~m}$ of water and suspended $5 \mathrm{~m}$ off the bottom. Seventy-five thousand Moi (Pacific Threadfin, Polydactylus sexfilis) were placed inside the cage in April 1999. These fish are fed several hundred pounds of commercial fish feed daily. As the fish grow the amount of feed required increases, as does the amount of waste they produce. Some of the food drops through the cage onto the sand bottom below. Some of this may be utilized by the benthos. The fish waste also accumulates directly below and around the cage depending on the currents. This study examined the effects of excess nutrification on the benthic invertebrate community. Special attention has been paid to the infaunal invertebrate community (those animals living in the sand). Two of the goals of this study were to identify any potential indicator species and to ascertain the implications of excessive fish feed loading of sand bottoms off O'ahu. Analysis of benthic samples has shown an increase in a dorvilleid polychaete, which was correlated with increased feed amounts and fish size. After fish were harvested from the cage the dorvilleid population returned to previous numerical levels. No other major changes were noted in the infaunal community. Preliminary conclusions are that nutrification of the benthos below the cage did not negatively impact the infaunal community.

\section{Alterations of Hawaiian Stream Habitat and Their Effects on Stream Biota: A Field Study and Microcosm Experiments Charles Cbong ${ }^{4}$}

Two different types of studies conducted by the University of Hawai'i Zoology Department have addressed the question of how artificial alterations of stream habitat may affect invertebrate faunas in Hawai'i. In the first study, samples of benthic invertebrates were collected from sites just upstream and downstream of Wainiha Dam, Kaua'i, from 1994 to 1996 , to determine the effects of the dam on stream biota. Five randomly placed Hess samples of $0.1 \mathrm{~m}^{2}$ were collected within each 30-m-long site on a monthly basis. In September 1994, a spate lowered the height of the dam by approximately $5 \mathrm{~cm}$, thereby

\footnotetext{
${ }^{3}$ Department of Zoology, University of Hawai'i at Mānoa, Honolulu, Hawai'i 96822. Sponsor: Julie Brock.

${ }^{4}$ Department of Zoology, University of Hawai'i at Mānoa, Honolulu, Hawai'i 96822 . Sponsor: R. A. Kinzie III.
}

allowing flow over the dam for a greater percentage of time. The change in flow regime corresponded to a sustained increase in density and biomass of benthic invertebrates found above and below the dam. In the second study, two alien species of decapod crustaceans, Macrobrachium lar and Procambarus clarkii, were compared with an endemic $\mathrm{Ha}-$ waiian decapod, Atyoides bisulcata, in their ability to process various types of leaves. Water flow was maintained through a rectangular trough holding 60 microcosms made from 15-liter plastic food containers. Five grams of dried leaves were placed in the microcosms and allowed to condition for 2 days before one species of crustacean was introduced into each container for 14-17 days. The mean leaf mass loss per day was then calculated and compared between treatments and to controls. Results indicated that certain 
types of riparian vegetation provide food for the alien decapods, but not for $A$. bisulcata. These studies suggest that both stream di- versions and the spread of alien riparian flora may have contributed to the decline in abundance of native Hawaiian stream animals.

\section{Metamorphosis in a Marine Gastropod: The Role of Transcription Kimberly A. del Carmen ${ }^{5}$}

The paradigm for metamorphosis in invertebrates is based on model systems such as Manduca sexta where morphogenic changes are controlled by hormones, that activate transcription factors. Metamorphosis in the marine gastropod Phestilla sibogae is a rapid and drastic transition from a planktonic larval stage to a benthic juvenile stage. The role of transcription in metamorphosis in P. sibogae is not completely understood. Past work in our laboratory indicates that metamorphosis is not blocked by transcription or translation inhibitors. The objective of this study was to further explore the role of transcription during metamorphosis of $P$. sibogae, and to answer the two questions: Do changes in the rate of transcription occur upon the induction of metamorphosis? To what extent does a known inhibitor of transcription inhibit metamorphosis in larvae of $P$. sibogae? By measuring the incorporation of $3 \mathrm{H}$-uridine into RNA we found that there is a drastic increase in the rate of transcription that begins within the first hour of induction and peaks at about $8 \mathrm{hr}$. Using the same method, we also confirmed that the pharmacological agent DRB reduces transcription in $P$. sibogae. Transcription is inhibited by $80 \%$ within the first hour of metamorphic induction, but because DRB breaks down in solution, transcription is inhibited by less than $25 \%$ by hour four. Further assays showed that activation of the receptor for the metamorphic signal is not affected by a reduction in transcription. However, this reduced transcription slows the metamorphic progression, suggesting that new transcription is critical to completion of metamorphosis in $P$. sibogae.

\section{Hypophysectomy and Hormonal Replacement Therapy Effects on Osmoregulatory Ability of the Channel Catfish, Ictalurus punctatus Steve M. Eckert ${ }^{6}$}

When channel catfish in fresh water (FW) were hypophysectomized, plasma osmolality decreased significantly after $24 \mathrm{hr}$, and maximum reduction was seen after 2 days. When they were transferred from FW to dilute seawater $(20-40 \% \mathrm{SW})$, the plasma osmolality of the sham-operated (intact) fish was consistently higher than that of environmental

\footnotetext{
${ }^{5}$ Department of Zoology and Pacific Biomedical Research Center, Kewalo Marine Laboratory, University of Hawai'i at Mānoa, Honolulu, Hawai'i 96822. Sponsor: Michael G. Hadfield.

${ }^{6}$ Department of Zoology and Hawai'i Institute of Marine Biology, University of Hawai'i at Mānoa, Honolulu, Hawai'i 96822. Sponsor: E. Gordon Grau.
}

water, whereas the osmolality of the hypophysectomized fish was equivalent to the environmental salinity. Thus, the catfish seems to be unable to hypo-osmoregulate or unable to reverse the direction of the ion pump in a saline environment, while hypophysectomized fish behave like an osmoconformer. Ovine PRL restored the reduced osmolality of the hypophysectomized fish in FW to the level of that of the sham-operated fish. Cortisol was also effective, but the effect was less pronounced than the effect of PRL. Injection of PRL in combination with cortisol resulted in a marked increase in plasma osmolality to a level above that of the sham-operated fish. $\mathrm{GH}$ was without effect. Replacement therapy 
in the hypophysectomized fish transferred to dilute SW revealed essentially the same results as in the fish in FW. PRL and cortisol increased the osmolality to the level of that of the sham-operated fish. A synergistic effect of PRL and cortisol was also apparent; the plasma osmolality increased above that of the sham-operated fish. In the stenohaline catfish, both PRL and cortisol seem to be substantially involved in the ion uptake from the environment not only in FW but also in a saline environment.

\section{Conservation of the OrangeBlack Hawaiian Damselfly (Megalagrion xanthomelas) on O'ahu \\ Kate Fobnson ${ }^{7}$}

The Orangeblack Hawaiian Damselfly (Megalagrion xanthomelas) is a formerly common endemic lowland species in Hawai'i. On $\mathrm{O}^{\prime}$ ahu it has been reduced to a single remnant population in a short section of stream lacking alien fish species. The objective of this study was to establish a second population of $M$. xantbomelas in a natural stream habitat on O'ahu. Adults and naiads of $M$. xanthomelas were translocated and monitored using mark- recapture methods. Although there was good adult survival in the translocated population and reproductive behavior was observed, $M$. xantbomelas failed to establish a viable population in the new habitat, possibly because of the presence of alien crayfish in the stream. Megalagrion xanthomelas is a good candidate for future translocation attempts if an appropriate stream without alien predators can be located.

\section{Using Molecular Data to Determine Species Boundaries in Hawaiian Corals ${ }^{8}$ Amy Lacks ${ }^{9}$}

It has been estimated that there are over 800 species of stony corals in the world's oceans. Many of these are difficult to distinguish because of high intraspecific variation in skeletal characteristics according to depth and location, and corallite variation within individuals. Using a combination of genetic and morphological data may be the most accurate way to

${ }^{7}$ Department of Zoology and Ecology, Evolution, and Conservation Biology Program, University of $\mathrm{Ha}-$ wai'i at Mānoa, Honolulu, Hawai'i 96822. Sponsor: Sheila Conant.

${ }^{8}$ Coauthors are C. L. Hunter, Waikīkī Aquarium, University of Hawai'i at Mānoa, Honolulu, Hawai' $i$ 96822, and C. W. Morden, Department of Botany, University of Hawai'i at Mānoa, Honolulu, Hawai'i 96822. I also acknowledge help from the Botany 662 class, University of Hawai'i at Mānoa, and the Center for Conservation Research and Training, University of Hawai' $i$ at Mānoa, Honolulu, Hawai'i 96822, for providing sequencing.

${ }^{9}$ Department of Zoology, University of Hawai'i at Mānoa, Honolulu, Hawai'i 96822. Sponsor: Paul Jokiel, Hawai'i Institute of Marine Biology, University of Hawai'i at Mānoa, Honolulu, Hawai'i 96822. interpret species boundaries in corals. This study tested the utility of using different molecular characters to clarify species boundaries in Hawaiian corals. Corals belonging to four different species in the genus Porites were collected from Lanikai, $\mathrm{O}^{\prime}$ ahu: $P$. compressa, $P$. lobata, $P$. evermanni, and an unnamed fourth species that is currently being described. DNA was extracted and a region of the cytochrome c oxidase subunit 1 (COI) gene was amplified. The resulting 393 base pair sequences exhibited almost no intra- or interspecific variation, suggesting that the region has been conserved within this genus. The base pair variations resulted in no amino acid substitutions. Comparing these data with sequences from Caribbean corals revealed that this gene region may be useful in distinguishing families, but is not suitable for species-level comparisons. Randomly amplified polymorphic DNA (RAPD) analysis is currently under way, and preliminary evidence suggests that it has potential to distinguish boundaries between some species. 


\section{Growth-Promoting Effects of a Recombinant Mammalian Growth Hormone on the Euryhaline Tilapia \\ Thomas Leedom ${ }^{10}$}

Experiments were undertaken to evaluate the growth-promoting effects of recombinant bovine growth hormone ( $\mathrm{rbGH})$ in the tilapia (Oreochromis mossambicus). Previous experiments have shown rbGH to be effective in stimulating growth in a variety of teleost species. The investigation was divided into two parts. The first series of studies was to establish optimal hormonal dosages, animal size, and rearing temperatures. Different animal sizes $(1,15$, and $30 \mathrm{~g}$ ), water temperatures $\left(22,26\right.$, and $\left.30^{\circ} \mathrm{C}\right)$, and hormone doses $(0.1$, 1.0 , and $10.0 \mu \mathrm{g} / \mathrm{g}$ body weight) constituted the experimental variables. No significant differences in growth were observed in any treatment group compared with their respec- tive controls, except for a significant increase in growth with increased water temperature. The second series of experiments examined the efficacy of three different modes of hormone delivery. Experimental fish were immersed in $10 \mathrm{mg}$ rbGH per liter, injected with $0.1,1.0$, or $10.0 \mu \mathrm{g} / \mathrm{g}$, or fed feed containing $\mathrm{rbGH}(10 \mu \mathrm{g} / \mathrm{g}$ body weight). Hormone injection was found to be the most efficient delivery, followed by immersion and feeding. Further studies are in progress to evaluate the effect of rbGH treatment on insulinlike growth factor (IGF-I) gene expression and on augmentation of plasma immunoglobulin levels $(\operatorname{IgM})$ as an indication of possible immune responses to rbGH.

\section{Testing Assumptions of Reef Fish Diversity Models through Dietary Analysis Ken Longenecker ${ }^{11}$}

Reef fish diversity models implicitly or explicitly assume that food choice and availability do not influence community structure. I analyzed gut contents from cryptic fishes found in the spur-and-groove habitat outside Kāne'ohe Bay, O'ahu, Hawai'i, to test the explicit assumptions that reef fishes have broad dietary overlap and are highly opportunistic. I examined dietary overlap by identifying, to species, the gammaridean amphipods eaten by 20 individuals from each of five species known to feed primarily on amphipods. BrayCurtis percentage similarity values between each fish species pair, calculated using the number of each amphipod species eaten,

${ }^{10}$ Department of Animal Sciences and Hawai'i Institute of Marine Biology, University of Hawai'i at Mānoa, Honolulu, Hawai'i 96822. Sponsor: E. Gordon Grau.

${ }^{11}$ Department of Zoology and Hawai'i Institute of Marine Biology, University of Hawai'i, Honolulu, Hawai'i 96822 . Sponsor: David W. Greenfield. ranged from 0 to $32.4 \%$, indicating that overlap is low. When all prey are identified to higher taxonomic categories, as in the studies upon which reef fish diversity models are based, similarity ranges from 28.9 to $83.3 \%$. The assumption of broad dietary overlap in reef fishes appears to be an artifact of the lack of detail in past dietary studies. I examined opportunism by comparing the diets of all cryptic fishes collected on dates when phyllosome larvae, calanoid copepods, or zoeae were either absent or highly abundant. The number of these plankton eaten did not significantly increase when they were abundant, suggesting that opportunism is low in cryptic fishes. Reef fish diversity models may be overlooking a factor capable of structuring communities. I propose that specialized diets may allow the high species richness seen in coral reef fishes. The relative abundance of these fishes may be controlled by the availability of important prey. 


\section{Rain Forest Restoration-Directed Dispersal into Regenerating Habitat}

Timothy D. Male ${ }^{12}$

The majority of rain forest plant species produce fleshy fruit and rely on vertebrates to disperse their seeds to suitable habitat for germination and growth. I studied seed dispersal in and near an Australian rain forest and found that seed dispersers spent substantial amounts of time outside rain forest in areas where forest was regenerating. They spent time in and dispersed rain forest seeds to this habitat because they were feeding on the seeds of the single fleshy-fruited species present, Endiandra sieberi (Lauraceae). Seed traps under fruiting $E$. sieberi in regenerating forest captured 10 to 55 times more rain forest seeds than traps under nonfruiting trees in regenerating forest. Seedlings of those rain forest species were 5 to 25 times more abundant under $E$. sieberi than in adjacent re- generating forest habitat. Further, $89 \%$ of visits of radio-tagged or randomly encountered frugivores in regenerating habitat occurred during the fruiting season of $E$. sieber $i$ $(n=117)$. Over $90 \%$ of rain forest seeds were deposited in seed traps during that time; all seeds were of rain forest species that fruited at the same time as $E$. sieberi. This same subset of rain forest plant species was also disproportionately represented in seedling samples. These eight rain forest species comprised over $65 \%$ of seedlings surveyed. These data suggest that frugivores are not only moving substantial numbers of seeds into regenerating forest habitat, but that the subset of plant species whose seeds they disperse will dominate newly reforested areas.

\section{Vegetation Structure and Seedling Ecophysiology in a Hawaiian Dry Forest ${ }^{13}$ Mónica Mejía-Chang ${ }^{14}$}

The objectives of this study were to investigate the floristic composition (seedlings and adults) of different habitats (forest understory, forest gaps, and open sites dominated by invasive grass) in the Kānepu'u dry forest preserve, island of Lāna'i, and to analyze survivorship and physiological response of the two most common species naturally regenerating in the study site: Diospyros sandwicensis (a native species) and Lantana camara (an invasive species). The forest understory sites were less diverse than both the forest gap and grassland sites in terms of seedling composition. For adults, the grassland sites were

12 Department of Zoology, University of Hawai' $i$ at Mānoa, Honolulu, Hawai'i 96822. Sponsor: Leonard Freed.

${ }^{13}$ Funds were received from the Cooperative Park Service Unit and the Ecology, Evolution, and Conservation Biology Program, University of Hawai'i at Mānoa, Honolulu, Hawai'i 96822.

${ }^{14}$ Department of Botany, University of Hawai'i at Mānoa, Honolulu, Hawai'i 96822. Sponsor: Guillermo Goldstein. less diverse than both the forest understory sites and the forest gap. Invasive species represented more than $50 \%$ of the species found in the studied sites. For the second component of the study, Lantana camara seedlings suffered the highest percentage of mortality under forest understory conditions $(30 \%$ versus $10 \%$ in the forest gap sites). The native species Diospyros sandwicensis suffered high mortality in the open grassland sites $(70 \%)$ and forest gap (30\%) compared with the forest understory (15\%). Lantana camara seedlings were able to achieve higher photosynthetic rates and to recover a higher percentage of their photosynthetic potential after induced photoinhibition. Seedlings of the native species were under more water stress, as suggested by the results on predawn and midday water potential. The results of this study suggest that the standing native tree community is not well represented at seedling level in the more pristine remnant of forest patches in the Kānepu'u preserve. Also, $L$. camara seedlings showed a better potential 
to cope with high light levels and drought conditions. This can place them in a more favorable position to survive and establish compared with native species.

\section{Why Do Snails Hide? Microhabitat Use by Five Species of Littorinidae ${ }^{15}$ Dwayne Minton ${ }^{16}$}

Littorinid gastropods, which are conspicuous members of the supralittoral community, occupy pit and crevice microhabitats more frequently than numerous exposed surface microhabitats. Previous work suggested that sheltered microhabitats may ameliorate mortality from temperature-related stresses, particularly desiccation and heat coma. I determined the relative survival rate of five Caribbean littorinid species (Cenchritis muricatus, Tectarius antonii, Nodilittorina anguistior, N. dilatata, N. ziczac) in pit, crevice, and exposed surface microhabitats when exposed to heat coma temperatures (HCT), and I also examined the use of and the competition for these microhabitats by littorinids in the field as a possible mechanism to explain the distributions of these species. In the field, pits and crevices were significantly cooler than exposed surfaces, but gastropod body tem- perature did not vary by microhabitat for any of the five species investigated. All snails had a body temperature approximately equal to the ambient temperature, which during this study was below the HCT for all species. Gastropod shell size was correlated with pit and crevice dimensions. When exposed to HCT in the laboratory, individuals occupying different microhabitats had the same survival rate for all species except $T$. antonii and $N$. anguistior, for which individuals occupying the sheltered microhabitats had a significantly higher survival rate than individuals on exposed surfaces. Patterns of microhabitat use in the laboratory suggested that size-related competition for sheltered microhabitats may occur among these species, but results from a field competition experiment did not support that observation.

\section{Structural Homology of the Melon Fly (Bactrocera cucurbitae) White Eye Gene and That of Other Fruit Flies Nathan Peabody ${ }^{17}$}

Techniques for inserting and stably integrating genes are crucial to our future ability to develop new means of managing economically important insect pest species in an environmentally friendly manner. With several

15 The research for this study was done at Hofstra University Marine Laboratory, St. Ann, Jamaica, West Indies.

${ }^{16}$ Department of Zoology, University of Hawai'i at Mānoa, Honolulu, Hawai'i 96822. Sponsor: E. Alison Kay.

17 Department of Entomology, University of Hawai' $i$ at Mānoa, Honolulu, Hawai'i 96822. Sponsor: Susan McCombs. potential methods available for inserting DNA, it is critical to determine the most accurate and efficient methods for detecting transformed individuals. Our goal is the detection of transformants by mutant rescue, using visual screening for individuals that regain wild-type eye pigmentation after insertion of the wild-type gene. Initially, we wanted to obtain the wild-type cDNA of the white eye gene of the melon fly, Bactrocera cucurbitae (Coquillett), for use as a selectable marker in germline transformation in that species. Second, we wanted to establish the basis of the melon fly white eye (we) mutation to ensure that the we strain can act as a host for mutant rescue. The we gene is composed 
of seven exons (1, 2, 3, 4a, 4b, 5, and 6) and six introns $(1,2,3,4 \mathrm{a}, 4 \mathrm{~b}$, and 5). Approximately $95 \%$ of the melon fly white eye gene has been sequenced from polymerase chain reaction products from both the wild type and mutant strains. The $3^{\prime}$ tail of the mRNA was analyzed by $3^{\prime}$ rapid amplification of cDNA ends (RACE). The consensus sequence showed a high degree of homology to other fruit fly white eye sequences. The pu- tative protein has $>95 \%$ homology with three other tephritids, $\sim 85 \%$ with Drosopbila melanogaster, and $\sim 84 \%$ with Lucilia cuprina. The multispecies pileup indicates definitively that the sequence obtained is the white eye gene because of its protein homology, specifically in the transmembrane and ATP-binding regions. Recent data suggest that the mutation may be from a failure to splice intron $4 \mathrm{~b}$ from the mRNA.

\section{How Many Reef Fishes Are We Missing?: Patterns of New Species Discovery on Deep Coral Reefs in the Indo-Pacific \\ Richard Pyle 18}

In 1989 I began developing the use of mixedgas scuba and other "technical" diving techniques as a tool for ichthyological investigation of deep (60-150 m) coral reefs and have conducted initial exploratory expeditions to the Cook Islands, Papua New Guinea, and Palau. These expeditions yielded over 200 specimens of deep-reef fishes, comprising more than 100 species representing 20 different families. Among these are more than 50 new species, three-fourths of which belong to the families Labridae, Gobiidae, and Serranidae, and the rest are among nine other families. The number of new species within each family parallels that of the overall deep-reef species assemblage, except for Apogonidae with a total of seven collected species, none of which were new. Comprehensive analysis of specimens and videotape surveys of the ichthyofauna at one $90-\mathrm{m}$ site in Palau suggests that over $70 \%$ of the species inhabiting this depth are undescribed. New species assemblages on deep reefs show comparatively low distributional overlap (both between different island groups and between sites within each island group), suggesting higher rates of endemism than for shallow-reef assemblages. Based on these and other observed patterns, it is clear that many more species remain to be discovered on Indo-Pacific deep coral reefs.

\section{Gonadal Steroids Effects on Growth Hormone Release in the Tilapia, Oreocbromis mossambicus \\ Larry G. Riley ${ }^{19}$}

In the tilapia, Oreochromis mossambicus, males are larger than females. To study this sexually dimorphic pattern in somatic growth, I examined the effects of gonadal steroids $(17 \beta$ -

${ }^{18}$ Department of Zoology, University of Hawai'i at Mānoa, Honolulu, Hawai'i 96822. Sponsor: John E. Randall.

${ }^{19}$ Department of Zoology and Hawaici Institute of Marine Biology, University of Hawai'i at Mānoa, Honolulu, Hawai'i 96822. Sponsor: E. Gordon Grau. estradiol, testosterone, and dihydrotestosterone) on release of growth hormone (GH) from the pituitary in vivo and in vitro. For the in vivo study, tilapia were injected with $5 \mu \mathrm{g} /$ $\mathrm{g}$ body weight of steroid or vehicle three times over an 11-day period. Plasma GH levels in control female fish were significantly higher than those of control males. Females treated with testosterone, which can be converted to $17 \beta$-estradiol at the tissue, had significantly higher plasma GH levels compared with control males. Treatment of males with 
$17 \beta$-estradiol or females with dihydrotestosterone, which is not converted to $17 \beta$ estradiol at the tissue, had no effect on plasma $\mathrm{GH}$ levels. Pituitaries from male tilapia were incubated in a static culture for $24 \mathrm{hr}$ with 5 , 50 , or $500 \mathrm{nM}$ of $17 \beta$-estradiol, testosterone, or dihydrotestosterone. At 1, 4, 8, 12, and $24 \mathrm{hr}$ an aliquot of incubation media was taken and analyzed for $\mathrm{GH}$ levels. There was no difference in $\mathrm{GH}$ release between control males and females. Testosterone at $50 \mathrm{nM}$ significantly elevated GH release after $24 \mathrm{hr}$ of incubation. However, $17 \beta$-estradiol and dihydrotestosterone had no effect. These data suggest that there is a sexually dimorphic pattern of plasma $\mathrm{GH}$ in the tilapia. This pattern, to some extent, appears to be regulated by the gonadal steroids at the level of the pituitary. However, gonadal steroids might be altering the effect of neuroendocrine factors that stimulate or inhibit GH release from the pituitary.

\section{The Early Bee Gets the Buzz: Competition between Bee Species ${ }^{20}$ Guinnevere Roberts ${ }^{21}$}

Recent findings suggest that introduced honey bees (Apis mellifera) negatively impact native pollinators through exploitative competition for shared nectar and pollen resources. I investigated whether honey bees and native stingless bees (Trigona spp.) exhibit temperature-related differences in worker activity patterns in subtropical Queensland, Australia. I found that honey bee workers regularly leave their hive at a temperature of $15^{\circ} \mathrm{C}$, but Trigona workers do not become active until the ambient temperature reaches $18^{\circ} \mathrm{C}$. During winter months, temperatures below $18^{\circ} \mathrm{C}$ are common and tend to occur during the early morning and late afternoon. Because most plant species exhibit peaks of pollen anthesis and nectar secretion at dawn or in the early evening irrespective of temperature, the honey bees' greater tolerance for cool weather gives this species a competitive advantage over the native Trigona species. I tracked pollen availability at Xanthorrboea jobnsonii flowers, a species that flowers during the cool spring months, and found that $>90 \%$ of their pollen resources were depleted by the time Trigona workers were able to start foraging. Thus, interspecific differences in temperature thresholds provide a mechanism through which honey bee populations can outcompete Trigona spp. for floral resources.

\section{Hawaiian Endemic Succineid Land Snails: Preliminary Study of Phylogeny and Biogeography Rebecca 7. Rundell ${ }^{22}$}

The Hawaiian land snail fauna is extraordinarily diverse and unique, and an ideal model for evolutionary study. Hawai'i is home to at

\footnotetext{
${ }^{20}$ Financial support for this research was provided by grants from the National Science Foundation and the Ecology, Evolution, and Conservation Biology Program at the University of Hawai'i at Mānoa, Honolulu, Hawai'i 96822.

${ }^{21}$ Department of Zoology, University of Hawai'i at Mānoa, Honolulu, Hawai'i 96822. Sponsor: L. Freed.

22 Department of Zoology, University of Hawai' $i$ at Mānoa, Honolulu, Hawai'i 96822. Sponsor: Robert H. Cowie.
}

least 750 mostly endemic nonmarine snail species; unfortunately 70 to $90 \%$ of these are now extinct. Succineidae are among the few Hawaiian land snails that have remained relatively abundant. Succineids can be found around the world, but only in Hawai' $i$ have they adopted such a broad range of habitats, from xeric duneland to montane rain forest. Despite the evolutionary and ecological significance of the endemic Hawaiian succineids, almost no research on this group has been undertaken since the early 1900 s. The process of evolutionary radiation in this group 
can be investigated by constructing a phylogenetic tree of the Hawaiian Succineidae using molecular techniques and by evaluating range sizes of the succineid species using museum specimens and relating this to island age (older islands are hypothesized to have species with smaller ranges), in the context of the "taxon cycle" hypothesis of adaptive radiation. In this study, I examined a subset of the Hawaiian Succineidae, testing the utility of $16 \mathrm{~S}$ rRNA and COI genes for phylogenetic reconstruction in this group. $16 \mathrm{~S} \mathrm{rDNA}$ may be less informative for assessing relationships among Hawaiian succineids than COI. Preliminary results for two species suggest that species on older islands do indeed have smaller ranges, but additional data are needed to confirm or reject this.

\section{Osmoreception in the Euryhaline Tilapia, Oreochromis mossambicus ${ }^{23}$ Andre P. Seale ${ }^{24}$}

In the tilapia (Oreocbromis mossambicus), as in many teleosts, prolactin (PRL) plays a central role in freshwater (FW) osmoregulation, acting on all osmoregulatory surfaces to reduce ion and water permeability and increase the retention of solutes. Consistent with these actions, the release of both forms of PRL found in this species, $\mathrm{PRL}_{177}$ and $\mathrm{PRL}_{188}$, is stimulated both in vitro and in vivo, as extracellular osmolality is reduced. The ability of osmolality to directly control the osmoregulatory output is an excellent and unique model system with which to elucidate the mechanisms by which an osmotic signal is transduced in an osmoreceptive cell. In the tilapia, hyposmotically induced PRL release in vitro is tightly correlated with an increase in cell size and dependent on extracellular calcium. In these experiments, the role of stretch-activated channels in the osmotic signal transduction was investigated using gado- linium $\left(\mathrm{Gd}^{3+}\right)$, a lanthanide ion known to block stretch-activated ion channels. Individual prolactin-containing rostral pars distalis (RPD) of the pituitary gland were incubated overnight in hyposmotic media $(300 \mathrm{mOsm} /$ $\mathrm{kg}$ ) with or without $\mathrm{Gd}^{3+}$, and samples were taken after 1 and $18 \mathrm{hr}$. Control tissues were incubated in hyperosmotic media (355 $\mathrm{mOsm} / \mathrm{kg}$ ). Although an inhibitory response of $\mathrm{Gd}^{3+}$ was not seen at $1 \mathrm{hr}$, significant inhibition of both $\mathrm{PRL}_{177}$ and $\mathrm{PRL}_{188}$ release in hyposmotic conditions was found after $18 \mathrm{hr}$ in the two highest doses of $\mathrm{Gd}^{3+}$ tested (100 and $1000 \mu \mathrm{M})$. These results suggest that stretch-activated ion channels play a role in the transduction of an osmotic signal in prolactin release. Studies using $\mathrm{Gd}^{3+}$ to uncouple cell size and PRL release, as well as to investigate the role of calcium in the early stages of this response, are currently ongoing.

\section{Herbivory and Nutrient Enrichment Effects on Benthic Community Structure and Development on a Hawaiian Reef fennifer E. Smith ${ }^{25}$}

Phase shifts from coral to algal dominance on coral reefs have become increasingly common

${ }^{23}$ Coauthor: N. Harold Richman.

${ }^{24}$ Department of Zoology and Hawai'i Insititute of Marine Biology, University of Hawai'i at Mānoa, Honolulu, Hawai'i 96822. Sponsor: E. Gordon Grau.

25 Department of Botany, University of Hawai'i at Mānoa, Honolulu, Hawai'i 96822. Sponsors: Celia Smith and Cynthia Hunter. over the last few decades and have driven researchers to identify potential causes leading to these shifts. Both top down (herbivory) and bottom up (nutrients) factors have been independently implicated as the primary causal mechanism affecting marine algal abundance on coral reefs. These hypotheses tend to be exclusive and do not consider interactive relationships between these two very different processes. It was earlier proposed that using 
the relative dominance model (RDM) the dominant benthic photosynthetic organisms could be predicted as a function of long-term exposure to both herbivory and nutrients. The goal of this study was to test the RDM experimentally in the field on a relatively unimpacted reef in Hawai'i. A randomized factorial block design was implemented to test the effects of herbivory and nutrient enrichment on benthic community development and structure on artificial settlement surfaces. Samples were collected every month for a 6month sampling interval, and biomass and species diversity parameters were assessed for several organismal categories. Algal biomass was greatest on experimental surfaces that were exposed to nutrient enrichment and herbivore exclusion simultaneously; fleshy algal biomass was greatest on surfaces removed from herbivory, and calcified algal biomass was greatest on surfaces exposed to nutrient enrichment. Species diversity estimates and successional patterns also exhibited significant treatment effects. This research shows that nutrient enrichment and herbivore exclusion can separately and synergistically support shifts in benthic algal community structure on tropical reefs.

\section{Love or Codependency? Monogamy, Pair-Bonding, Mate-Bonding, and Mate Guarding in the Butterflyfish, Chaetodon multicinctus David A. Strang ${ }^{26}$}

One of the most widely accepted explanations for the evolution of monogamy is the need for biparental care of the offspring. However, many species of monogamous fishes, such as the butterflyfishes, spawn their gametes into the water column and show no parental care. This presents a challenge to explain monogamy in such situations. Also, in any discussion of the evolution of social systems, it is important to bear in mind the distinction between selection for reproductive monogamy, for social monogamy, and for pair-bonding. Chaetodon multicinctus is a territorial, coralfeeding, socially monogamous, and strongly pair-bonded butterflyfish. Pairs of $C$. multi- cinctus spend approximately 60 to $70 \%$ of the time within $1 \mathrm{~m}$ of each other. I observed the behavior of both male and female pair-mates while in the presence of their mate and while separated from their mate on their territory. Both males and females fed at higher rates when in the presence of their mate, and they also showed higher rates of territorial defense in the presence of their mate. Therefore, this represents a strong selection pressure for members of a pair to stay close to one another and could explain the strong pair-bond in this species. Thus, if there is selection for a strong pair-bond, then social and reproductive monogamy might occur by default.

\section{Analyzing Reflectance Spectra of Corals for Use in Remote Sensing Robert Tomasetti ${ }^{27}$}

Effective use of airborne and satellite digital remote sensing of coral reefs requires spectral separation of reef community types and a knowledge of the changes in spectral re-

\footnotetext{
${ }^{26}$ Department of Zoology, University of Hawai'i at Mānoa, Honolulu, Hawai'i 96822. Sponsor: E. Reese.

${ }^{27}$ Department of Zoology, University of Hawai'i at Mānoa, Honolulu, Hawai'i 96822. Sponsor: Marlin Atkinson.
}

flectance with different environmental conditions. We measured pigment ratios and spectral reflectance of corals from high nitrate water (at the Waikiki Aquarium) using HPLC and an underwater fiber-optic spectroradiometer. Pigment ratios of coral tissue, normalized to peridinin, were $1.295 \pm 90 \%$ confidence limit of 0.138 for chlorophyll $a$, $0.477 \pm 0.039$ for chlorophyll $c_{2}, 0.054 \pm$ 0.005 for chlorophyllide $a, 0.021 \pm 0.003$ for $\beta$-carotene, $0.229 \pm 0.021$ for diadinoxanthin, 
and $0.017 \pm 0.006$ for diatoxanthin. Ratios of $\beta$-carotene and chlorophyll $a$ for corals in the Waikiki Aquarium were lower than pigment ratios from field corals at Puakō, Hawai'i $(0.29 \pm 0.11$ for $\beta$-carotene and $1.90 \pm 1.00$ for chlorophyll $a$ ). This probably indicates higher peridinin and lower accessory pigment concentrations resulting from increased zooxanthellae densities in Waikīkī Aquarium corals. We collected the reflectance spectra of 22 species of pan-Pacific corals in 11 genera from artificial systems at the Waikiki Aquarium with an underwater fiber-optic spectroradiometer. Fourth derivatives of their re- spective reflectances were computed to locate features in the spectra. Results were compared with over 200 in situ measurements of spectral reflectance taken of three species of coral in Kāne'ohe Bay, O'ahu, Hawai'i. Reflectance peaks did not vary significantly with increasing nitrate concentrations, but increasing nitrate caused greater variability among reflectance peaks located between 500 and $590 \mathrm{~nm}$. Changes in reflectance spectra of corals are relatively small with increasing levels of nitrate, so remote sensing algorithms will not detect whether corals have been exposed to high levels of nutrients.

\section{Sunscreen in Fishes: Ultraviolet Properties of Fish Slime ${ }^{28}$ fill P. Zamzow ${ }^{29}$}

Exposure to short-wavelength radiation is damaging to numerous organisms, including fishes. Shallow-dwelling tropical fishes are subjected to particularly high and variable levels of both UVA (320-400 nm) and UVB $(280-320 \mathrm{~nm})$ radiation. The presence of UVB-photoprotective factors in the skin of freshwater fishes has been suggested, and mycosporinelike amino acids (compounds with peak absorbance between 310 and

${ }^{28}$ I thank the members of N. J. Marshall's laboratory, VTHRC, University of Queensland, particularly N. J. Marshall and $\mathrm{K}$. Jennings. This work was supported by NSF OCE98-10387 and performed under IACUC protocol 95-012.

${ }^{29}$ Department of Zoology and Hawai'i Institute of Marine Biology, University of Hawai'i at Mānoa, Honolulu, Hawai'i 96822, and Heron Island Research Station, University of Queensland, Australia. Sponsor: George S. Losey.
$360 \mathrm{~nm}$ ) have been found in the eyes, fins, and eggs of fishes. Here I report the widespread distribution of both UVA- and UVBabsorbing compounds in the mucus of tropical marine fishes, as well as the inducibility of changes in the absorbance of mucus by UVA radiation. Mucus from 82 species (27 families) of shallow-dwelling fishes was examined by spectrophotometry and $94 \%$ were found to have strong absorbance peaks between 290 and $400 \mathrm{~nm}$. Peaks were categorized by approximate peak absorbance of ca. $290 \mathrm{~nm}$, $320-330 \mathrm{~nm}$, or $360 \mathrm{~nm}$. Most species (72\%) had absorbance peaks in more than one category, suggesting a broad-band ultraviolet screening function for their mucus. Thalassoma duperrey, a shallow-dwelling wrasse, alters the absorbance of its epithelial mucus in response to the UVA regime to which it is exposed, and in the wild, its mucus absorbance spectra change with depth. 